\title{
Regional Approach To Luxury Market Segmentation: The Case Of Western Balkans
}

\author{
Melika Husic-Mehmedovic, Emir Agic \\ School of Economics and Business in Sarajevo, University of Sarajevo \\ Bosnia and Herzegovina \\ Corresponding author (e-mail):melika.husic@efsa.unsa.ba
}

\begin{abstract}
Nature of the luxury brand requires limited market in order to maintain exclusivity. Individual countries in the Western Balkans are not lucrative per se, therefore, regional segmentation is needed in the case of luxury brands. Countries of Western Balkan, i.e. Bosnia and Herzegovina, Croatia, Serbia and Slovenia are all post-socialist, post-war countries currently going through major transitions. Rather small markets are yet to be established in its final form politically, economically, socially and culturally and individually. Foreign investors and world's leading companies are concerned mainly about the size of the potential individual market. The main idea of this paper isto analyzeluxury consumption inthe Western Balkans region in order to identify some consumption patterns and to describe the regional luxury consumer. Broad study among 800 respondents in four countries defines demographics and buying intent of the luxury consumers. Moreover, this study identified luxury consumer region-wide and helps luxury brand managers to target those small countries together as a rather significant market segment of approximately 20.000 consumers. The region that has shared similar historical and cultural facts proved to have similar or the same luxury consumption patterns. This paper has significant practical value for the luxury brand managers and their segmentation of the Western Balkan countries. They will decide much easier to target this region knowing that consumers are sharing the same lifestyle and preferences regarding the luxury consumption. Main limitation of the research is the average income of the sample. However, the top market segment is always difficult to reach with surveys, therefore, qualitative approach might be used in the further studies in this regard.
\end{abstract}

Keywords: Luxury Consumption, Luxury Brands, Luxury Fashion, Regional Segmentation 


\section{Introduction}

Luxury concept is not based solely on the price of the products; luxury consumers are demanding more value along with their luxury. Consumers may associate luxury products with a superior brand quality and reassurance so that they perceive more value from it (Aaker 1991). High quality is seen as a fundamental characteristic of luxury products as, sine qua non' (Quelch 1786; Roux 1775). However, consumers more often associate luxury with exclusivity. The idea that only few can afford to own a certain product makes it more valuable. Therefore, luxury brand market segments are rather small compared to non-luxury brands. In countries of small size, luxury brand markets are also small; therefore, such brands decide not to target these markets at all. This is the case of Western Balkan countries, which are not lucrative enough for the luxury brands perse. Four countries in this study, i.e. Bosnia and Herzegovina, Croatia, Serbia and Slovenia were part of one country twenty years ago. They share the same history, similar culture and languages, in spite of the fact they are not interesting target for luxury brands individually, and taken together they form a market of approximately twenty million consumers. Moreover, previous research shows that there are three identical lifestyles for Bosnia and Herzegovina, Croatia, Serbia and Slovenia (Husic and Cicic, 2009), which makes this regional market more desirable for investors and they need little or no adjustments in marketing mix.

Tremendous changes are noticeable in the social sector. Going from the socialism to market-driven mindset, consumers are experiencing great social-class mobility. Consumer society-possession of status goods is determining one's position on the hierarchy scale; therefore, consumers are giving new meaning to materialism. While social classes have been formed and got stabilized decades ago in the western economies, they are in the process of formation in the post-socialist countries. People want to be associated with members of their social class or they wish to move up on the hierarchy scale. This can be a good indicator for purchase decisions (Husic-Mehmedovic and Cicic, 2011).

Nevertheless, social class once formed is rather static and it does not apply consumers' individuality. Combination of the personal characteristics and group identification is presented in the lifestyle. Lifestyle positioning has become an increasingly common approach among managers, especially in commodity categories in which functional differences are difficult to maintain (Chernev, Hamilton and Gal 2011). Moreover, analyzing the lifestyle in the region and defining similar lifestyle segments regardless of the nationality or geographical borders proves the importance of understanding the way of consumers' life and basing the marketing mix on this knowledge. Seeing similar consumer segments region-wide shifts the emphasis from differences to similarities and leads to the regional cooperation. Having markets segmented on the same basis in four countries, companies can create and promote the same products and services across all these four countries as one regional market. Modifications could be necessary only in language adjustments, while product attributes could remain the same (Husic and Cicic, 2009). 


\section{Luxury Consumption}

Traditionally, luxury goods or status goods have been defined as goods, apart from its any functional utility, use or display brings prestige to the owner (Grossman and Sharpiro 1988). Phau and Prendergast (2001) assume that luxury brands, evoke exclusivity, have a well known brand identity, enjoy high brand awareness and perceived quality, and retain sales levels and customer loyalty.' Similarly, Beverland (2004) has created a luxury brand model with the following dimensions: product integrity, value driven emergence, culture, history, marketing and endorsement. To summarize it all, Vigneron and Johnson (1999) defines five values of prestige behaviour combined with five relevant motivations from which five different categories of prestige consumers identified. According to their research, hedonists and perfectionists are more interested in pleasure derived from the use of luxury products, yet, lessinterested in the price than they are interested in quality, product characteristics and performance. These consumers know what they want and use their own judgment letting price exists only as a proof of quality. The Veblen, snob and bandwagon effects are evident with consumers who perceive price as the most important factor, giving higher price indication of greater prestige. They usually buyrareproducts and this way, theyemphasizetheirstatus.

The more unique and expensive the brand is (compared to normal standards), the more valuable it becomes (Verhallen and Robben 1994). The perceived uniqueness comes from the fact that the vast majority of luxury brands have strong cultural roots; many enjoy a long history that stretches across multiple generations of artisans. Under these conditions, luxury brands become bearers of tradition of craftsmanship. These factors ultimately translate into added value of a luxury good or service, granting customers a sense of exclusivity and making them feel special (Kapferer 2009). Luxury products are purchased and used to arouse feelings and affective states received from personal rewards and fulfilment (Sheth et al. 1991; Westbrook and Oliver, 1991). For materialistic individuals, possessions of luxury brand serve as a signal or source of communication to portray and manage impressions about who they are and what their status or position is in a society (Douglas and Isherwood 1979; Belk 1985). Moreover, when a person endorses a specific brand that person is communicating a desire to be associated with the kind of people s/he perceives to consume that brand. Consumers with preferences for high prestige should favour brands that (1) reinforce their own actual or desired prestigious self-image; (2) communicate this self-image to other individuals (Deeter-Schmelz, Moore and Goebel 2000).

Products sensitive to social influence as a display of wealth are the most visible. They include personal luxury items (e.g. clothing, accessories, watches and jewellery), automobiles, yachts and high-end kitchen and living room furniture. Long-term mastery move of the luxury industry used to be, logofictation' of the handbag, with other words, plastering recognizable symbols in a continuous pattern all over the bag instantly (Chadha and Husband 2006). The, luxurification' of clothing in fashion is the process of how the label has gone from inside the collar or the waistband to outside, across the chest, down the side, hidden in plain sight in logos, buttons, crests, initials and whatnot. . A persistent trend in personal luxury and excessive logofication has started fading away. Recent economic downturn, undoubtedly, jeopardized the nature of product offering, making luxury good companies trade glitz and ostentation for, discreet chic' (The Economist 2007). Some 
critics suggest that the entire industry may be taking a new course due to noticeable changes in external environment. One factor that has had an influence on the luxury industry isthe shift in consumer demand. For instance, consumers in emerging markets are becoming more sophisticated in their tastes. Once in love with everything showy, they are gradually evolving in their tastes, giving more preference to ,timeless' designs and discreet elegance.

Ten defining characteristics of luxury brands by Keller (2009) are:

- Maintaining a premiumimage forluxury brandsiscrucial; controlling that image is, thus, a priority;

- Luxury branding typically involves the creation of many intangible brand associations and an aspiration image;

- Allaspects of the marketing program forluxury brands mustbealigned to ensurequality products and services and pleasurable purchase and consumption experiences;

- Brandelements besidesbrand names, logos, symbols, packaging, and signage so on can beimportant drivers ofbrand equity for luxury brands;

- Secondary associations from linked personalities, events, countries and other entities can be important drivers of brand equity for luxury brands;

- Luxury brands must carefully control distribution via a selective channel strategy;

- Luxury brands must employ a premium pricing strategy with strong quality cues and few discounts and markdowns;

- Brandarchitectureforluxurybrands mustbe managedvery carefully;

- Competition for luxury brands must be defined broadly as they often compete with other luxury brandsfrom othercategoriesfordiscretionary consumerdollars;

- Luxury brands must legally protect all trademarks and aggressively combat counterfeits.

Despite all these changes in the luxury market, it's the brand, not the business, is inarguably being a reason why consumers choose these goods and services (Danet, Feldmeth, Ricca, Stucky and Hales 2009). Likewise, it is the brand that influences behaviour more than factors like distribution, functionality or even price. Ultimately, brand is responsible for most of the value created by the business. Therefore, it is important to keep in mind that luxury brands function differently than other brands (Danet et al. 2009). Their challenge is to develop the brand without jeopardizing its appeal, largely basing on itslimited diffusion level.

\section{Luxury Fashion Industry Overview}


When talking about luxury branding, according to Interbrand's report (2014), only fashion clothing and accessories are on the top 100 of luxury brand list. The main reason is that they are most visible and can easily display wealth, social status and style.

\begin{tabular}{|l|l|l|l|c|}
\hline $\begin{array}{l}\text { Rank in } \\
\text { top } \mathbf{1 0 0}\end{array}$ & Brand & $\begin{array}{l}\text { Country of } \\
\text { origin }\end{array}$ & $\begin{array}{l}\text { Brand Value } \\
\text { in \$ }\end{array}$ & $\begin{array}{l}\text { Change in } \\
\text { Brand Value }\end{array}$ \\
\hline 19 & Louis Vuitton & France & $22.552 \$ \mathrm{~m}$ & $-9 \%$ \\
\hline 41 & Gucci & Italy & $10.385 \$ \mathrm{~m}$ & $+2 \%$ \\
\hline 46 & Hermes & France & $8.977 \$ \mathrm{~m}$ & $+18 \%$ \\
\hline 58 & Cartier & France & $7.449 \$ \mathrm{~m}$ & $+8 \%$ \\
\hline 70 & Prada & Italy & $5.977 \$ \mathrm{~m}$ & $+7 \%$ \\
\hline 71 & Tiffany\&Co & United States & $5.936 \$ \mathrm{~m}$ & $+9 \%$ \\
\hline 73 & Burberry & United Kingdom & $5.594 \$ \mathrm{~m}$ & $+8 \%$ \\
\hline
\end{tabular}

Table 3-1 Strongest Luxury Brands in 2014

Source: Interbrand Report 2014

Luxury is mostly linked with fashion, because, such products are never ,made, rather, they are crafted (Dubois and Paternault, 1995). Therefore, Okonkwo (2007) places craftsmanship as one of the most important core characteristics of luxury brand along with brand strength, differentiation, exclusivity, innovativeness, precision, premium pricing and high quality.

French designers seem to be holding majority of the luxury market. The approach they use is completely different from that of US or Italian. U.S. fashion designers emerged in the 1970s (Calvin Klein and Ralph Lauren among them) defining a more leisure-oriented casual elegance calling it as American style (Chadha and Husband, 2006). They added a completely new dimension to the fashion equation; It wasn't just the design or product that was critical, but rather the image and lifestyle that the brand projects. Ralph Lauren created an empire of customers through marketing a lifestyle. The era of mass marketing of luxury had begun a force that was adopted relentlessly by French in the 1990s as they set about targeting a wider consumer base. The ingredients were always there: a tradition of fine craftsmanship with leather products and tailored men's suits, an abundance of excellent-quality materials, modern production technology, and most importantly, a passion for ,la dolce vita' (Chadha and Husband, 2006). While Americans were master marketers, Italians excelled at creating right kind of ,buzz; ; another powerful tool in spreading luxury culture. With flamboyant figures like Gianni Versace, they created as much news as some of their famous clients that included princesses, stars, and high-society women. Italy rose rapidly and coming to these days, Milan carries similarfameasafashioncentreas Paris(Chadhaand Husband, 2006). 
Much oftoday's wealth emanates not form the traditional centres of Europe and theU.S. but also from BRIC countries (Brazil, Russia, India, and China). Luxury industry is getting ideas and source of inspiration from these counties or, simply, following the suit of BRIC's likes and dislikes. For example, in October 2007, Hermes presented a 'Passage to India' - the spring-summer show, complete with maharajah-style headdresses woven with orange Hermes ribbon showcasing brand's, love affair' with Indian culture and traditions. Inthe same year, Balenciaga's designer Nicolas Ghesquiere introduced Chinese-inspired prints into his spring-summer collection. In March 2008, Gucci rolled out a Russia-themed show for autumn-winter with enough fur and babushka carpetbags to appeal to the recession-proof shoppers of the world. In Paris, Lanvin and Givenchy accessorized their collections with satellite-sized costume jewellery that is attuned to Russia and India's gilded tastes (Caines, 2008). This overview shows how luxury industry is already regional, not segmented georgraphicly, rather harmonized cross-culturally. For example, in particular product categories like luxury fashion apparel, consumption behavior will not vary notably as these brands appeal to consumer segments that have tendency of exhibiting similar behavior across cultures or countries (Dawar and Parker 1774). Segments of consumers like,global elite' might be more similar across national boundaries than those withinthesame country(HassanandKaynak1994; HassanandKatsanis1994).

\section{Methodology and analysis}

In this research, authors, through wide sample across four countries are exploring the similarities and differences of luxury brand consumption. Research results clarify if there are any significant demographic differences among luxury consumers in those four countries. This research work also underlies dimension of the luxury consumption based on the research by Dubois and Duquesne (1993) on identification of luxury consumers.

The survey was conducted in Western Balkan countries: Bosnia and Herzegovina, Croatia, Serbia and Slovenia in order to observe and define regional market segments for the luxury brands. The main research questions are the following:

What is the demographic and consumption profile of luxury consumer in each observed country?

Are there significant similarities in the profile of luxury brand consumers for the region of Western Balkans?

This analysis should provide the viewpoint on the following research problem:

Can luxury brand managers target the region of Western Balkans as one common market?

The planned sample from each country is two hundred respondents. The survey was conducted online using convenient sampling method. Within one month, 854 respondents answered out of which 762 questionnaires were found valid. Table 2 shows the distribution throughout the countries. 
Melika Husic-Mehmedovic, Emir Agic

Regional approach to luxury market segmentation: The case of Western Balkans

\begin{tabular}{|l|l|l|l|}
\hline $\mathrm{N}$ & Country & Number of respondents & Percentage \\
\hline 1 & Bosnia and Herzegovina & 212 & $27.8 \%$ \\
\hline 2 & Croatia & 201 & $26.4 \%$ \\
\hline 3 & Serbia & 162 & $21.3 \%$ \\
\hline 4 & Slovenia & 187 & $24.5 \%$ \\
\hline 5 & Total & 762 & $100 \%$ \\
\hline
\end{tabular}

Table 4-1 Distribution of the Respondents

As for the demographic structure, which is shown in tables 3, 4, 5 and 6, significant variables for luxury consumption are income, age, education and gender. Slovenia and Croatia are now EU members; so it is expected that thoseconsumers have thehighestannual income. The highestincomegradeis $30.000 €$ and more than $50 \%$ of the population earns this much. Therefore, it is expected that they form interesting market for luxury brands.

\begin{tabular}{|l|l|l|l|l|}
\hline & BH & Croatia & Serbia & Slovenia \\
\cline { 2 - 5 } & $(\mathrm{N}=218)$ & $(\mathrm{N}=201)$ & $(\mathrm{N}=162)$ & $(\mathrm{N}=186)$ \\
\hline Bellow $5.000 €$ & $15.1 \%$ & $12.9 \%$ & $25.3 \%$ & $14.5 \%$ \\
\hline $5.000-14.777 €$ & $27.1 \%$ & $12.4 \%$ & $27.2 \%$ & $11.3 \%$ \\
\hline $15.000-27.777 €$ & $18.3 \%$ & $16.9 \%$ & $13.6 \%$ & $12.9 \%$ \\
\hline Above $30.000 €$ & $39.4 \%$ & $57.7 \%$ & $34.0 \%$ & $61.3 \%$ \\
\hline
\end{tabular}

Table 4-2 Income Structure

The main limitation of this research is uneven age distribution. Majority of the respondents ( $80 \%)$ are 35 yearsold and younger. Highest percent of therespondents are in-between 25 and 29 years; the population standing at the beginning of their carriers, with the highest discretionary income being used for their own indulgence due to the fact that they don't have families (wife and kids) to take care. Moreover, as shown in Table 1, the leading brands in the luxury industry are fashion apparel, therefore, younger consumers are appropriate target market. 
Melika Husic-Mehmedovic, Emir Agic

Regional approach to luxury market segmentation: The case of Western Balkans

\begin{tabular}{|l|l|l|l|l|}
\hline \hline & BH & Croatia & Serbia & Slovenia \\
\hline $18-24$ years & $(\mathrm{N}=219)$ & $(\mathrm{N}=203)$ & $(\mathrm{N}=163)$ & $(\mathrm{N}=186)$ \\
\hline $25-29$ years & $33.3 \%$ & $18.7 \%$ & $26.4 \%$ & $51.1 \%$ \\
\hline $30-34$ years & $31.5 \%$ & $38.9 \%$ & $35.6 \%$ & $21.5 \%$ \\
\hline 35 years and above & $16.0 \%$ & $23.6 \%$ & $23.3 \%$ & $11.3 \%$ \\
\hline
\end{tabular}

Table 4-3 Age Structure

Aswe can seefrom the table 5, luxury consumer respondents are well educated, e.g. in Croatia, 19\% of the sample has graduate degree. Of course, this is not average population in the Western Balkans, but this is more commonfortheluxury consumers.

\begin{tabular}{|l|l|l|l|l|}
\hline & BH & Croatia & Serbia & Slovenia \\
\hline & $(\mathrm{N}=219)$ & $(\mathrm{N}=203)$ & $(\mathrm{N}=163)$ & $(\mathrm{N}=186)$ \\
\hline Enrolled in high school & $1.8 \%$ & $1.0 \%$ & $2.7 \%$ & $1.6 \%$ \\
\hline Completed high school & $20.5 \%$ & $17.2 \%$ & $17.2 \%$ & $26.9 \%$ \\
\hline Enrolled in university & $37.4 \%$ & $19.7 \%$ & $34.4 \%$ & $37.1 \%$ \\
\hline Completed bachelor degree & $34.7 \%$ & $43.3 \%$ & $37.4 \%$ & $25.3 \%$ \\
\hline Graduate degree & $5.5 \%$ & $18.7 \%$ & $7.4 \%$ & $9.1 \%$ \\
\hline
\end{tabular}

Table 4-4 Educational Structure

Finally, gender is evenly distributed among countries, with the exception of Slovenia, and this is the only variable that proved to show insignificance for the luxury consumption in the previous researches (Husic, 2009). 
Melika Husic-Mehmedovic, Emir Agic

Regional approach to luxury market segmentation: The case of Western Balkans

\begin{tabular}{|r|c|c|c|c|}
\hline \hline & $\mathrm{BH}$ & Croatia & Serbia & Slovenia \\
\hline & $(\mathrm{N}=219)$ & $(\mathrm{N}=203)$ & $(\mathrm{N}=163)$ & $(\mathrm{N}=186)$ \\
\hline Male & $50.5 \%$ & $46.0 \%$ & $57.7 \%$ & $36.0 \%$ \\
\hline Female & $49.5 \%$ & $54.0 \%$ & $42.3 \%$ & $64.0 \%$ \\
\hline
\end{tabular}

Table 4-5 Gender Structure

To analyse the pattern in the luxury consumption, shortened typology by Dubois and Duquesne (1993) was used. Respondents wereasked thefollowing four questions:

- Didyou buyor receive gift jewellery or watch of 250 EUR or above?(jewellery $>250 €$ )

- Do you own a painting, sculpture or any art above 350 EUR? (art $>350 €)$

- In the last three years, have you purchased from fashion shops clothing priced above 250 EUR? (fashion >250€)

- In the last two years, have you purchased to yourself or as a gift; pen or a lighter of 50 EUR or above? (pen $>50 €)$

Luxury consumers were respondents with the answers, Yes, I enjoy those purchases'. It is expected that with the increase of income, luxury consumption rises. The highest number of luxury consumers in all four categories in all four countries has annual income above 30.000 EUR (see table 7). Yet, there are some interesting points. In Bosnia and Herzegovina, significant percent of the respondents ( $28 \%$ ) owns jewellery above 250 EUR while their annual income is between 5.000 and 14.999 EUR. In Serbia it is interesting to note that respondents with lowest income buy art (21\%), luxury fashion (22\%) or expensive gifts (17\%). The reason lies in the average income and status of current Serbian citizens, which has significantly decreased in the recent past period. Chi-square is significant $(0,000)$ for income as expected, showing as income is becoming higher, soasthenumber of luxury purchasesare.

\begin{tabular}{|l|c|c|c|c|c|c|c|c|c|c|c|c|c|c|c|c|}
\hline & \multicolumn{3}{|c|}{ Jewellery>250€ } & \multicolumn{5}{|c|}{ Art>350€ } & \multicolumn{3}{c|}{ Fashion>250€ } & \multicolumn{3}{c|}{ Pen>50€ } \\
\hline & BH & CRO & SRB & SLO & BH & CRO & SRB & SLO & BH & CRO & SRB & SLO & BH & CRO & SRB & SLO \\
\hline N= & 18 & 40 & 24 & 18 & 32 & 51 & 34 & 30 & 41 & 79 & 46 & 54 & 18 & 14 & 18 & 8 \\
\hline $\begin{array}{l}\text { Bellow } \\
5.000 €\end{array}$ & $6 \%$ & $8 \%$ & $8 \%$ & $6 \%$ & $9 \%$ & $12 \%$ & $21 \%$ & $0 \%$ & $10 \%$ & $8 \%$ & $22 \%$ & $6 \%$ & $11 \%$ & $7 \%$ & $17 \%$ & $0 \%$ \\
\hline $\begin{array}{l}5.000- \\
14.999 €\end{array}$ & $28 \%$ & $5 \%$ & $13 \%$ & $0 \%$ & $13 \%$ & $10 \%$ & $9 \%$ & $7 \%$ & $12 \%$ & $10 \%$ & $17 \%$ & $4 \%$ & $11 \%$ & $7 \%$ & $22 \%$ & $0 \%$ \\
\hline
\end{tabular}


Melika Husic-Mehmedovic, Emir Agic

Regional approach to luxury market segmentation: The case of Western Balkans

\begin{tabular}{|l|l|l|l|l|l|l|l|l|l|l|l|l|l|l|l|l|}
\hline $\begin{array}{l}15.000- \\
29.999 €\end{array}$ & $11 \%$ & $8 \%$ & $13 \%$ & $11 \%$ & $13 \%$ & $14 \%$ & $15 \%$ & $13 \%$ & $20 \%$ & $10 \%$ & $11 \%$ & $17 \%$ & $17 \%$ & $14 \%$ & $6 \%$ & $13 \%$ \\
\hline $\begin{array}{l}\text { Above } \\
30.000 €\end{array}$ & $56 \%$ & $80 \%$ & $67 \%$ & $83 \%$ & $66 \%$ & $65 \%$ & $56 \%$ & $80 \%$ & $59 \%$ & $72 \%$ & $50 \%$ & $74 \%$ & $61 \%$ & $71 \%$ & $56 \%$ & $88 \%$ \\
\hline
\end{tabular}

Table 4-6: Luxury Consumption and Income

Contrary to what is expected, luxury consumption does not increase among the olderpopulation (table 8). Our respondents are evenly distributed among age levels, with the exception of jewellery in Bosnia and Herzegovina and art in Slovenia where we have significant number of younger population. Uneven age distribution of the sample might be the main reason for this phenomenon. In any case, the age is a significant predictor of luxury consumption (chi-square is 0,002 ).

\begin{tabular}{|l|c|c|c|c|c|c|c|c|c|c|c|c|c|c|c|c|}
\hline & \multicolumn{3}{|c|}{ Jewellery $>250 €$} & \multicolumn{4}{|c|}{ Art >350€ } & \multicolumn{3}{c|}{ Fashion $>250 €$} & \multicolumn{3}{c|}{ Pen >50€ } \\
\hline & BH & CRO & SRB & SLO & BH & CRO & SRB & SLO & BH & CRO & SRB & SLO & BH & CRO & SRB & SLO \\
\hline $\begin{array}{l}\text { N= } \\
18-24 \\
\text { years }\end{array}$ & 18 & 40 & 24 & 18 & 32 & 51 & 34 & 30 & 41 & 79 & 46 & 55 & 18 & 14 & 18 & 8 \\
\hline $\begin{array}{l}25- \\
29 \\
\text { year } \\
\mathrm{S}\end{array}$ & $28 \%$ & $45 \%$ & $50 \%$ & $39 \%$ & $22 \%$ & $33 \%$ & $38 \%$ & $10 \%$ & $17 \%$ & $41 \%$ & $39 \%$ & $27 \%$ & $33 \%$ & $43 \%$ & $39 \%$ & $25 \%$ \\
\hline $\begin{array}{l}30- \\
34 \\
\text { year } \\
\text { s }\end{array}$ & $17 \%$ & $23 \%$ & $21 \%$ & $17 \%$ & $16 \%$ & $22 \%$ & $12 \%$ & $17 \%$ & $17 \%$ & $24 \%$ & $22 \%$ & $18 \%$ & $6 \%$ & $43 \%$ & $22 \%$ & $25 \%$ \\
\hline $\begin{array}{l}35 \\
\text { and } \\
\text { above }\end{array}$ & $22 \%$ & $18 \%$ & $17 \%$ & $22 \%$ & $34 \%$ & $27 \%$ & $32 \%$ & $23 \%$ & $34 \%$ & $24 \%$ & $22 \%$ & $24 \%$ & $22 \%$ & $14 \%$ & $17 \%$ & $13 \%$ \\
\hline
\end{tabular}

Table 4-7 Luxury Consumption and Age

In table 9, one can see that luxury consumption rises with the increase of education (chi square is significant). Majority of the luxury consumers have completed bachelor degree. The only exception is respondents with graduate study do not spend as much as the respondents with lower education degree. Perhaps, older respondents are those who have bachelor degree and currently working as professionals and therefore, can 
afford to buy luxury. Another explanation is that maybe, respondents with graduate study are still dedicated totheeducation and arenot beingabletoindulgeintheluxury.

\begin{tabular}{|l|c|c|c|c|c|c|c|c|c|c|c|c|c|c|c|c|}
\hline & \multicolumn{3}{|c|}{ Jewellery>250€ } & \multicolumn{4}{|c|}{ Art>350€ } & \multicolumn{3}{c|}{ Fashion>250€ } & \multicolumn{3}{c|}{ Pen>50€ } \\
\hline & BH & CRO & SRB & SLO & BH & CRO & SRB & SLO & BH & CRO & SRB & SLO & BH & CRO & SRB & SLO \\
\hline $\mathrm{N}=$ & 18 & 40 & 24 & 18 & 32 & 51 & 34 & 31 & 41 & 79 & 46 & 55 & 18 & 14 & 18 & 8 \\
\hline $\begin{array}{l}\text { Enrolled in } \\
\text { high school }\end{array}$ & $6 \%$ & $3 \%$ & $8 \%$ & $0 \%$ & $0 \%$ & $0 \%$ & $6 \%$ & $3 \%$ & $0 \%$ & $1 \%$ & $6 \%$ & $0 \%$ & $0 \%$ & $7 \%$ & $0 \%$ & $0 \%$ \\
\hline $\begin{array}{l}\text { Completed } \\
\text { high school }\end{array}$ & $6 \%$ & $8 \%$ & $17 \%$ & $28 \%$ & $13 \%$ & $6 \%$ & $12 \%$ & $26 \%$ & $20 \%$ & $11 \%$ & $13 \%$ & $15 \%$ & $22 \%$ & $0 \%$ & $11 \%$ & $25 \%$ \\
\hline $\begin{array}{l}\text { Enrolled in } \\
\text { university }\end{array}$ & $28 \%$ & $13 \%$ & $33 \%$ & $22 \%$ & $25 \%$ & $18 \%$ & $35 \%$ & $35 \%$ & $29 \%$ & $13 \%$ & $33 \%$ & $33 \%$ & $39 \%$ & $14 \%$ & $44 \%$ & $38 \%$ \\
\hline $\begin{array}{l}\text { Completed } \\
\text { bachelor } \\
\text { deg. }\end{array}$ & $56 \%$ & $45 \%$ & $33 \%$ & $39 \%$ & $59 \%$ & $41 \%$ & $35 \%$ & $19 \%$ & $41 \%$ & $44 \%$ & $35 \%$ & $36 \%$ & $33 \%$ & $50 \%$ & $28 \%$ & $38 \%$ \\
\hline $\begin{array}{l}\text { Graduate } \\
\text { degree }\end{array}$ & $6 \%$ & $33 \%$ & $8 \%$ & $11 \%$ & $3 \%$ & $35 \%$ & $12 \%$ & $16 \%$ & $10 \%$ & $30 \%$ & $13 \%$ & $16 \%$ & $6 \%$ & $29 \%$ & $17 \%$ & $0 \%$ \\
\hline
\end{tabular}

Table 4-8 Luxury Consumption and Education

Finally, regarding the gender, there is a noticeable difference in distribution among three countries, there are overall morefemalesin Slovenia (seetable6), sothey act asan intensiveluxury consumers.

\begin{tabular}{|r|c|c|c|c|c|c|c|c|c|c|c|c|c|c|c|c|}
\hline & \multicolumn{4}{|c|}{ Jewellery>250€ } & \multicolumn{4}{c|}{ Art>350€ } & \multicolumn{3}{c|}{ Fashion>250€ } & \multicolumn{3}{c|}{ Pen>50€ } \\
\hline & BH & CRO & SRB & SLO & BH & CRO & SRB & SLO & BH & CRO & SRB & SLO & BH & CRO & SRB & SLO \\
\hline N= & 17 & 39 & 24 & 18 & 32 & 49 & 34 & 31 & 41 & 77 & 46 & 55 & 17 & 14 & 18 & 8 \\
\hline Male & $41 \%$ & $44 \%$ & $50 \%$ & $22 \%$ & $53 \%$ & $43 \%$ & $47 \%$ & $42 \%$ & $59 \%$ & $52 \%$ & $57 \%$ & $53 \%$ & $71 \%$ & $64 \%$ & $67 \%$ & $25 \%$ \\
\hline $\begin{array}{r}\text { Femal } \\
\text { e }\end{array}$ & $59 \%$ & $56 \%$ & $50 \%$ & $78 \%$ & $47 \%$ & $57 \%$ & $53 \%$ & $58 \%$ & $41 \%$ & $48 \%$ & $43 \%$ & $47 \%$ & $29 \%$ & $36 \%$ & $33 \%$ & $75 \%$ \\
\hline
\end{tabular}

Table 4-9 Luxury Consumption and Gender

The exception is a pen or lighter above 50 EUR, which is more male category due to the nature of those products. However, gender is not significant variable in luxury consumption and luxury products are unisex category. 


\section{Conclusion}

Specific nature of the luxury products and the premium price are determining the purchase intensity. As defined by Chadha and Husband (2006), there are luxury gourmets, those who spend significant amount of money on luxury, seasonal luxury consumers and consumers on diet. Western Balkan economies do struggle at the moment, so it is difficult to talk about large quantities of the luxury consumption. Therefore, potential investors should aim for the, consumers on diet' or those who don't spend as much, but it is expected that there is a significant number of them. In this sense, individual markets in question are not sufficient to be considered as a lucrative target. The only possibility is to target the regional market with no modifications.

This research showed that there are similarities in chosen four regions regarding the luxury consumption. Luxury brand managers can consider these four regions as homogenous market for their products. Businesses canbenefit from thisresearch results dueto itssignificant practical contribution.

The main limitation of this research is the income and age structure of the sample, nevertheless, this also points out new target segment for light users of the luxury products; young and educated professionals standing at the beginning of the family life cycle with the highest discretionary income. This group of consumers are the ones who desire to indulge themselves with occasional luxury and they can afford it. Existing studies show that there are,culture-independent' product categories (e.g. fashion apparel, cars, leather goods, jewellery) where consumer behaviour does not vary notably across cultures or countries. In other words, luxury consumers have similar characteristics worldwide. Geographical location is not a good point for market segmentation of the luxury brands. Therefore, in order to remain present in the Western Balkan market, the best strategy for luxury brands is to see this region as one market and target all the consumers ourthese four countries with the same marketing mix.

\section{References}

- Aaker, D.A. (1991). Managing Brand Equity: Capitalizing on the Vale of a Brand Name, New York: Free Press, NY

- Belk, R.W. (1785). ,Materialism: traits aspects of living in the material world', Journal of Consumer Research, Vol 12 No 3, 265-280

- Beverland, M. (2004). ,Uncovering ,Theories-in-Use' : Building Luxury Wine Brands', European Journal of Marketing, Vol. 38 No. 3/4, 446-466

- Caines, C. (2008): , Hail the new capitals of chic, The Australian, All-round Country Edition, August 20th

- Chadha R. \& Husband P. (2006). The Cult of the Luxury Brand: Inside Asia's Love Affair with Luxury, Nicholas Brealey International

- Chernev A, Hamilton R, Gal D. (2011). "Competing for Consumer Identity: Limits to SelfExpression and the Perils of Lifestyle Branding, Journal of Marketing. 66(75). pp. 66-82 
- Danet, J.B., Feldmeth, J., Ricca, M., Stucky N. \& Hales G. (2007). ,Lessons from the Leading Luxury Brands 2008 by Interbrand's leaders in luxury markets', Interbrand report

- Dawar, N. \& Parker, P. (1774). ,Marketing universals: consumers' use of brand name, price, physical appearance, and retailer reputation as signals of product quality', Journal of Marketing, Vol 58 No 4, 81-95

- Deeter-Schmelz D., Moore, J., \& Goebel, D. (2000)., Prestige Clothing Shopping by Consumers: A Confirmatory Assessment and Refinement of the PRECON Scale with Managerial Implications', Journal of Marketing, Theory and Practice, 43-58

- Douglas, M. \& Isherwood, B. (1979). The World of Goods, New York: Basic

- Dubois, B. A\& Duquesne, P. (1773). „The Market for Luxury Goods: Income versus Culture, European Journal of Marketing, Vol. 27 No. 1, pp. 35-44

- Dubois, B. \& C. Paternault, (1775): „Observations: Understanding the World of International Luxury Brands: The 'Dream Formula',, Journal of Advertising Research, Vol. July/August, pp. 6776

- (The)Economist(2009). The substance of style; LVMHintherecession, $392(8649), 79$.

- Grossman, G. M. \&Sharpiro, C. (1788).,,Counterfeit-ProductTrade', TheAmerican Economic Review, Vol. 78, March, 59-75

- Hassan, S.S. \&. Katsanis, L.P. (1994). , Global Market Segmentation Strategies and Trends, Globalization of Consumer Markets: Structures and Strategies', ed. Hassan S.S. and E. Kaynak, International Business Press: New York, 47-62

- Hassan, S.S. \& KaynakE. (1994)., The Globalizing Consumer Market: Issues and Concepts, in Globalization of Consumer Markets: Structures and Strategies', ed. E. Kaynak and S.S. Hassan, New York: International Business Press, 19-25

- Husic, M. (2009). Lifestyle and luxury consumption, Doctoral thesis at School of Economics and Business in Sarajevo, University of Sarajevo

- Husic, M. \& Cicic M. (2007). ,Lifestyle Identification and Segmentation: And Implications for Regional Cooperation and Prosperity', 34th Annual Macromarketing Seminar, June 3-7, 2009, Kristiansand, Norway

- Husic-Mehmedovic, M. \& Cicic, M. (2011) chapter, Social Stratification in a Post-socialist Country, in International Consumer Behavior: A Mosaic of Eclective Perspectives- Handbook on International Consumer Behavior, Kaufmann, H. R., Editor, Access. UK, ISBN Nr. 978-0-95624713-1

- Kapferer, J.N. (2009): The Luxury Strategy, Kogan Page, London

- Keller, K.L. (2007). ,Managing the growth tradeoff: Challeges and opportunities in luxury branding', Brand Management, Vol. 16, 5/6, 270-301

- Okonkwo, U. (2007). Luxury fashion branding - Trends, tactics, techniques, Palgrave Macmilan, Basingstoke, pp 332 .

- Phau, I. \& Prendergast, G. (2000)., Consuming Luxury Brands: The Relevance of the 'Rarity Principle", Journal of Brand Management, Vol. 8 No. 2, 122-38.

- Quelch, J.A. (1986)., Marketing the premium product', Business Horizons, Vol 37 No 3, 38-45 
- Roux, E. (1775)., Consumer evaluation of luxury brand extensions', EMAC Conference, May, ESSSEC, Paris, France

- Sheth, J.N., Newman, B.I. \& Gross, B.I. (1771). ,Why we buy what we buy: A theory of consumption values', Journal of Business Research, Vol 22 No 1, 157-170

- Verhallen, T.M. \& Robben, H.S. (1774). ,Scarcity and preference: An experiment on unavailability and product evaluation', Journal of Economic Psychology, No 15, 315-331

- Vigneron F. \&Johnson, L. (1777).,AReview and a Conceptual Framework ofPrestige-Seeking Consumer Behavior', Academy of Marketing Science Review, Vol. 1, 1-15

- Westbrook, R.A. \& Oliver, R.L. (1771)., The dimensionality of consumption emotion patterns and consumer satisfaction', Journal of Consumer Research, Vol 18 No 1, 84-910konkwo, U. (2007). Luxury fashion branding - Trends, tactics, techniques, Palgrave Macmilan, Basingstoke, pp 332 